\title{
La guerra contra los japoneses en México durante la Segunda Guerra Mundial: Kiso Tsuru y Masao Imuro, migrantes vigilados
}

DOI: $10.32870 /$ mycp.v4i10.480

Marcela Méndez Vázquez ${ }^{1}$

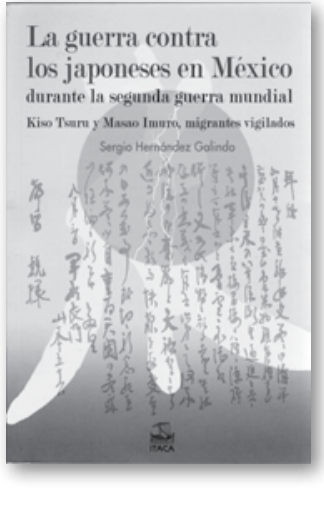

La guerra contra

los japoneses en México

Kiso Tuaru y Masao Imure, migrantes vigileden

Laguerra contra los japoneses en México durante la Segunda Guerra Mundial: Kiso Tsuru y Masao Imuro, migrantes vigilados (2011), Sergio Hernández Galindo, Editorial Ítaca, México, ISBN: 978-607-7947-21-8.

La guerra contra los japoneses en México durante la segunda guerra mundial: Kiso Tsuru y Masao Imuro, migrantes vigilados, aporta al campo de los estudios de la diáspora japonesa, la historia diplomática y la historia política. Entrelazando las historias de vida de dos inmigrantes japoneses vigilados, con evidencias de fuentes mexicanas, estadounidenses y niponas, Hernández Galindo muestra el impacto de las políticas que afectaron a la comunidad japonesa residente en México antes y después del conflicto, analizando la relación compleja entre las tres naciones, con sus implicaciones más allá del Atlántico. Su afirmación central de que el conflicto entre Estados Unidos y Japón, en México tenía el triple objetivo de apropiarse de recursos estratégicos, posicionar su estructura de inteligencia y utilizar o anular a la comunidad japonesa

1. Doctora en Estudios de Asia y África con especialidad en Japón, por El Colegio de México, A. C. Investigadora independiente. Correo electrónico: mendezcastelar@hotmail.com 
(p. 14), es desarrollada por el autor extensamente con sustento en documentos del Archivo General de la Nación, Secretaría de Gobernación, Dirección de Investigaciones Políticas y Sociales; de la Universidad Autónoma de Baja California; y del Archivo de Abelardo L. Rodríguez. En Estados Unidos, con la investigación en los Archivos Nacionales y Administración de Documentos (NARA) y en la Biblioteca Presidencial Franklin D. Roosevelt. Sobre Japón utilizó el archivo de Shiozo Ogino y el Archivo de Migrantes de la ciudad de Yokohama. Asimismo realizó entrevistas al señor Masao Imuro, a los hijos del fallecido doctor Kiso Tsuru, y a otros miembros de la comunidad japonesa.

La guerra contra los japoneses contiene tres capítulos precedidos por los agradecimientos y la introducción, acompañados de una cronología, un índice de figuras y fotografías, listado de archivos consultados y una bibliografía de 93 libros y artículos; 102 notas al pie, 12 figuras y tres fotos.

En el capítulo uno, "La disputa por la comunidad japonesa durante la Segunda Guerra Mundial”, se presentan el contexto de la emigración japonesa a partir de la era Meiji (1868-1912), los hechos relevantes del enfrentamiento entre Estados Unidos y Japón, y las políticas de México instaurando la guerra interna cuyas acciones específicas afectaron en México a más de 6,000 nipones (p. 34). El autor traza el cambio desde la promoción de la migración hacia América, y cómo se fue incrementando en Estados Unidos el temor del Gobierno y de los sectores xenofóbicos, a medida que los japoneses y sus descendientes se afincaban en su territorio y ascendían socialmente. Las comunidades prosperaban a lo largo de California, en agricultura, pesca y pequeñas industrias, en ambos lados de la frontera.

En el contexto internacional, el punto de cambio fue la victoria japonesa frente a Rusia en 1905. Japón dejaba de ser la víctima de los tratados desiguales y Estados Unidos comenzó a considerarlo como potencia militar, y a sus nacionales en el exterior como un nuevo "peligro amarillo". La expansión imperial japonesa fue acompañada del otro lado del Pacífico por rumores y campañas racistas en California, y finalmente, por medidas que iban a implicar el traslado hacia México de muchos japoneses, como el Pacto de Caballeros de 1907. En 1911, Estados Unidos comenzó el pedido de informes a sus embajadas en Latinoamérica sobre las actividades de los japoneses. La organización en asociaciones educativas o de coterráneos que mantenían lazos solidarios con la metrópoli fue vista con desconfianza por las autoridades de los países de acogida. La idea de que eran peligrosos era propagada por el Gobierno estadounidense como propaganda para justificar la represión e infundir miedo 
antinipón en su población (p. 30). Así, en 1924 se cierran las fronteras de Estados Unidos a japoneses.

Las reacciones de los residentes nipones distaron de la homogeneidad que les atribuían los gobiernos a sus comunidades. Clases, ocupaciones, arraigo, redes locales y transnacionales influyeron en su posicionamiento. El autor muestra a la comunidad en México en un campo de fuerzas entre la presión del primero, de Estados Unidos y la presión de Japón, pero sobre todo, injustamente tratados como traidores a las órdenes del imperio nipón dispuestos a una invasión continental. Paralelo a las actividades de inteligencia de los tres países, Hernández Galindo muestra cómo las embajadas japonesas insistían para involucrar a los migrantes para apoyar la adquisición de materiales y la generación de divisas; cómo Estados Unidos aseguraba el continente del Polo Norte a la Patagonia y hacía inteligencia y campaña en contra de las comunidades antes del conflicto armado (p. 44); y cómo el cardenismo pasó de favorecer las relaciones comerciales, las inversiones y la compra de petróleo por los japoneses (p. 47), al posterior traslado forzoso o encierro durante el gobierno de Ávila Camacho y a difundir la supuesta invasión japonesa para lograr la aceptación de la impopular alianza estratégica con Estados Unidos (p. 30).

El autor dedica los dos capítulos finales a los migrantes Kiso Tsuru y Masao Imuro, quienes al momento de estallar la guerra eran los japoneses más vigilados por el espionaje estadounidense en México. De extracciones sociales diferentes, se narran sus historias de vida, vinculando sus actividades a la inteligencia antijaponesa a la que fueron sometidos.

En el capítulo dos, "Kiso Tsuru: el empresario de guerra", se presenta la veloz y exitosa carrera del inmigrante en la trama de las relaciones tri y multilaterales. El doctor Tsuru, oriundo de Oita-ken, llegó a México a los 24 años como secretario de embajada en 1918, y reingresó en 1920 representando a una firma de Yokohama de exportación e importación de artículos japoneses y mexicanos. En 1928 fundó su primera compañía farmacéutica, y en casi 20 años había participado en la industria pesquera, en proyectos de infraestructura, y había fundado al menos dos petroleras, y una compañía comercial internacional para reemplazar a la primera en 1938, cuando sus negocios se habían diversificado y exportaba materias primas que la expansión bélica japonesa requería. Sus contactos con políticos y empresarios mexicanos y con empresarios, funcionarios y diplomáticos japoneses, lo convirtieron en una pieza clave para las adquisiciones petroleras y de materias primas, 
antes y después de la expropiación. Esto atrajo la atención de Washington: el FBI lo seguía desde 1935, pero también la inteligencia militar, naval y, en México, la Secretaría de Gobernación. De igual forma, sus contactos con políticos mexicanos le evitaron cargos de espionaje y la cárcel. Aun cuando sus empresas fueron confiscadas en 1942 al declararse la guerra a Japón bajo la presidencia de Manuel Ávila Camacho, no compartió el destino de la mayoría de sus connacionales.

En el capítulo tercero y final, "Masao Imuro: el prisionero de guerra", el autor desvela la historia de un joven de 20 años, llegado de su Nagoya natal en enero de 1941, para trabajar en una comercializadora e importadora de porcelana y azulejos. El joven emprendedor con estudios primarios, vivía en una habitación de la casa de su patrón. No era militante ni tenía contactos en la política. Cuando Imuro fue detenido el 25 de mayo de 1942 por considerarse "extranjero peligroso", cayó en la cuenta de que las cartas enviadas a amigos japoneses habían sido interceptadas por la inteligencia mexicana y por la estadounidense (p. 103). Llenas de orgullo patriótico y de exabruptos juveniles de amenazas de ataques al Canal de Panamá, al presidente Roosevelt y críticas al presidente Ávila Camacho, sus opiniones le valdrían siete años de cárcel. Desde mayo de 1942 pasaría por las Islas Marías (Nayarit), Perote (Veracruz), Lecumberri y el Centro de Detención para Menores en Tlalpan (ambos en el DF). Finalmente logró su libertad en marzo de 1949, cuando el presidente Miguel Alemán lo indultó, considerándose extinguidas las causas de su detención.

La posibilidad de la entrevista con el protagonista, permite al autor narrar una descripción cercana y directa del inmigrante Imuro, diferente de la de Tsuru (reconstruida a partir de documentos y testimonios de familiares y otros). Son vívidas su rutina cotidiana, sus impresiones de un México de abundancia, contrastando con el Japón militarizado en el que creció. Un sistema en el que los niños eran incorporados al esfuerzo bélico y que tenía al emperador (Tenno) como eje del sistema político y fuerza de cohesión nacional, una fuerza que a esas alturas no permitía debate alguno (pp. 106, 125 y 129). No obstante, Imuro había evitado el reclutamiento con su partida a México; no pudo evitar la vigilancia, la cárcel, y su valor potencial para un canje de prisioneros de extenderse el conflicto. Como si su destino fuera inexorable, explica el investigador (pp. 108-114), concluyendo el capítulo con el cierre de la historia del joven. 
El volumen, cuya primera edición apareció en 2011, es completo, atractivo, informativo y su contribución es única, reconociéndose el parentesco académico con la línea rigurosa trazada por María Elena Ota Mishima, cuya obra el autor reconoce. Recientemente han aparecido obras sobre el tema, como la de García (2014), lo que no quita a la excelencia de la investigación, documentación y síntesis discutida. ${ }^{2}$

Las lecciones de la historia que el autor examina son tan válidas como hace 70 años. Nunca se encontró un plan para atentar contra personas o propiedades, ni hubo arrestos por terrorismo o sabotaje (p. 119). Claramente, la decisión de la concentración significó una regresión en los derechos de los ciudadanos y un reforzamiento del sistema autoritario, "de discrecionalidad contra los enemigos y opositores al gobierno [...] sin mediar proceso jurídico" (p. 59), dice Hernández Galindo. Y esto hace de La guerra contra los japoneses en México una obra actual e indispensable para pensar la democracia mexicana hoy.

2. García, Jerry (2014), Looking like the enemy: Japanese Mexicans, the Mexican state, and Us hegemony, 1897-1945, Arizona. 